\title{
Multigeruza polimerikoak: medikuntza-protesietarako materialen ezaugarriak hobetzeko bidea
} (Polymeric multilayers: A way of enhancing properties of medical prothesis)

\author{
Ainara Valverde, Leyre Pérez* \\ Kimika Makromolekularreko Laborategia, Kimika Fisikoa saila, \\ ZTF/FCT (UPV/EHU) \\ * leyre.perez@ehu.eus
}

DOI: $10.1387 /$ ekaia.17856

Laburpena: Biomedikuntza arloan inplante moduan erabiltzeko material berrien eskaera handia dago, baina errefus arazoak sortzen dituzte biobateragarritasun kontuak direla eta.

Lan honetan azalduko dugu nola eraldatu dugun bi substratu motaren gainazala. Bat ezorganikoa izango da eta bestea polimerikoa. Geruzaz geruzako («layer by layer») estrategiaz baliatuta, azido hialuroniko eta kitosanozko multigeruzak sortuko dira.

Kitosanoa fluoreszenteki markatu eta mikroskopio konfokalean fluoreszentziahazkundea behatu ondoren, ondorioztatu da geruzak modu arrakastatsu batean sortu direla. Honi esker, materialaren hidrofilitatea areagotzea lortu da, eta horrela, bakterioen aurkako gainazala lortzeaz gainera materialaren biobateragarritasuna handituko da modu merke eta sinple batean.

Hitz gakoak: Geruzaz geruzako, biobateragarri, kitosanoa, azido hialuronikoa.

\begin{abstract}
There is a great demand for new materials in the field of biomedicine to be used as implants, however they cause rejection problems due to their lack of biocompatibility. In this work two substrates (inorganic and polymeric) will be surface modified using the layer by layer strategy (LbL), in order to construct hyaluronic and chitosan multilayers. It has been proven that the layers were successfully built by fluorescent confocal microscopy by means of the increase of fluorescence along layers deposition after fluorescent labelling of chitosan. Thanks to this, it has been possible to increase the hydrophilicity of the surfaces enhancing antibacterial properties and getting more biocompatible materials in a simple and inexpensive way.
\end{abstract}

Keywords: Layer-by-layer, biocompatible, chitosan, hyaluronic acid. 


\section{SARRERA}

Hainbat mendetan zehar aztertu izan da bizi-kalitatea hobetzeko materialen erabilpena [1]. Guztiok ezagutzen ditugu, esaterako, duela ez hainbeste erabili izan diren inplante ezorganikoak, hala nola urrezko edota platinozko hortzak. Gaur egun, esparru honetan erabiltzen diren metalen artean titanioa da nagusi, eta ez soilik hortz-inplanteetan, artikulazioen protesietan ere. Izan ere, bere biobateragarritasun eta korrosioarekiko erresistentzia handiari esker, ez du alergiarik sortzen eta modu honetan errefuseko probabilitatea txikitu egiten du [2,3].

Azken urteotan polimeroek biomaterialen esparruan arreta handia bereganatu dute, haien moldakortasun paregabeari esker material metaliko edota zeramikoekin alderatuta. Polimeroek ekarpen handia ekarri dute materialen propietate fisiko, mekaniko eta kimikoei dagokienez, eta horrela, ahalbidetu da propietate espektro zabala egotea. Hori dela eta, ikerketa-biomaterial modura garatu dira material horiek azken hamarkadetan [4]

Hauen erabilera biomedikuntzan ugaria da: besteak beste, poliuretanozko bihotz artifizialak [5, 6], poliakrilonitrilozko dialisirako mintzak [7], edo polimetilmetakrilatozko ukipen lenteak [8].

Polimeroen artean polietilen tereftalatoak (PET) arreta handia jaso du biomaterial moduan dituen propietate fisiko-kimiko onei esker: propietate mekaniko eta garraio-propietate onak, egonkortasun termikoa eta gardentasun optikoa, eta bai biobateragarritasun ertaina [9] ere. Propietate hauek direla eta, zabaldu egin da PET-aren erabilera kateter eta inplante baskularrak, gernu-kateterrak, bihotz balbulak etab. egiteko.

Hala ere, polimeroek eta material ezorganikoek, giza gorputzean biobateragarritasun arazoak sortzen dituzte, eta azkenean errefusa gertatzen da. Horretaz gain, oso ohikoa da biomaterial baten inplantazioaren ondoren bakterioen pilatzeagatik biofilm bat sortzea. Biofilm bat mikrobio-komunitate bat da, matrize polimeriko organiko batean txertatua, eta gainazal batera itsatsia [10]. Biofilm hauek material sintetikozko inplanteetan eratu ohi dira (kateterretan, aldaka artifizialetan, hezur inplanteetan, ukipen-lenteetan...) [11], eta behin eratuta, zaila da antibiotikoen bidez konpontzea, biofilm hauek antibiotiko eta toxinetatik babesten dituztelako bakterioak [12]. Izan ere, neutralizatu egiten dituzte antibiotikoak eta toxinak, edo bestela, biofilmean barrena sartzea ekiditen dute [11]. Horregatik, gainazalaren eraldaketa izan daiteke bai material ezorganikoaren, bai material polimerikoen biobateragarritasuna handitzeko eta bakterioen aurkako ezaugarriak lortzeko modua.

Eraldaketa hauek egiteko aukera asko aztertu dira azken urteotan. Besteak beste, materiala hidrofilikoagoa bihur daiteke, horrela bere biobateragarritasuna handitu daitekeelako, eta bestalde frogatu da gainazal-energia 
txikiko materialak (hidrofilikoak) bakterioen adhesioarekiko erresistenteagoak direla gainazal hidrofoboak baino [13]. Ildo honetatik, bakterioen aurkako beste estrategia bat ikertzen ari da azken urteotan: "contact-killing» teknikan gainazalak berak kontaktuan hiltzen ditu bakterioak [14]. Propietate hau erakusten dute polisakarido batzuek, esaterako kitosanoak, bere karga dentsitate positibo handiari esker, disrupzioa eragiten du mikrobietan negatiboki kargatuta dagoen zelula-mintza [15].

Horretaz gainera, biobateragarritasunari lagundu diezaioketen beste aukera asko aipatu ahal dira, esate baterako, protesien integrazioa azeleratzeko endoteliko zelulei itsasteko gaitasuna hobetzen duten materialak [16], edo tronbosia ekiditen duten materialak [17].

Geruzaz geruzeko (LbL) deituriko metodologiak metodo anitz hauek bateratzeko aukera ematen du; horregatik arreta handia jaso du material ezberdinen gainazalen eraldaketa gauzatzeko metodo eraginkor gisa [18, 19]. Teknika honetan, materiala zenbait disoluziotan sartzen da. Material horietako geruzen artean indar sendo desberdinak sortzen dira eta ondorioz, erraz egin daitezke multigeruzak material baten gainazalean. Hala gertatzen da hidrogeno zubien kasuan [20, 21] edota elkarrekintza elektrostatikoen kasuan ere [22].

Polielektrolitodun multigeruzak, ingelesez polyelectrolyte multilayer (PEM) deiturikoak, elkarren segidako polikatioien eta polianioien adsortzioaren ondorioz eratzen dira, gainazal solido batean elkarrekintza elektrostatikoen bitartez [22] (1. irudia). Lortzen diren multigeruzek egonkortasun handia izan dezakete, askotan geruzen arteko gurutzamendua lortzen delako [23]. Gurutzamendu hau maximoa izateko, pHa kontuan izateko parametroa da. Izan ere, $\mathrm{pH}$-aren arabera polikatioien eta polianioien kargak kontrola daitezke, eta horrela, geruzen arteko gurutzamendua handitu egiten da [23].

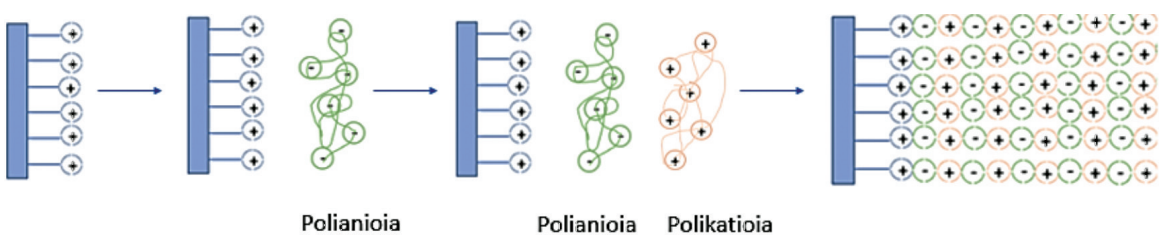

1.irudia. Polielektrolitodun multigeruzen eraketaren irudi eskematikoa.

Polikatioien eta polianioien naturaren arabera, multigeruzak propietate ezberdinak izango ditu, bakterioen aurka aritzean ez ezik, material substratuaren biobateragarritasuna handitzeko ere. Esaterako, Qinggang et al.-ek [17] polietilenimina/heparina multigeruzak eratu zituzten altzairu herdoilgaitzean; horrela, tronbosiaren aurkako materiala lortu zuten. Bes- 
tetik, Jonas et al.-ek [24] ugaztun- eta bakterio-zelulen itsaspena murrizten zuten hidrokarburo aromatiko polizikliko/azido poliakriliko multigeruzak lortu zituzten, eta $\mathrm{pH}$ baxuak erabiliz, geruzen arteko gurutzamendua handitzea lortu zuten.

Aipatutako polianioi eta polikatioi bezala, arreta handia bereganatu dute azken urteetan haien biobateragarritasunari esker zenbait polisakaridok, haien artean azido hialuroniko eta kitosano biopolimeroek.

Azido hialuronikoa (HA) (2A irudia) glukosaminoglikano lineal bat da, azido $\beta$-(1,4)- $D$-glukuronido eta $\beta$ - $(1,3)-N$-azetil- $D$-glukosamina disakaridoen unitate errepikatuekin osatua $[25,26]$. HA konposatu oso hidrofilikoa da, biobateragarria eta biodegradagarria[26]; beraz biomaterial moduan oso egokia da. Bestalde, bere egituran azido karboxilikoak ditu eta bere pka 3-4 bitartekoa denez, pH zabal batean negatiboki kargatuta dago [27] eta polianioi moduan erabil daiteke polielektrolitodun multigeruzetan. Horretaz gainera, bakterioen itsaspena ekidin dezake bere hidratazio konstanteari esker, eta bai lortzen den gainazal energia baxuari esker[13]. Sei Kwang et al.-ek [28], egiaztatu zuten azido hialuronikoak gainazalaren hidrofilitatea handitzen zuela HA/poly-l-lysina multigeruzak eratuz beiran.

Kitosanoa $(\mathrm{CHI})(2 \mathrm{~B}$ irudia) $(1 \rightarrow 4)$ lotutako $N$-azetil- $\beta$ - $D$-glukosamina eta $\beta$ - $D$-glukosamina monomerodun ausazko kopolimeroa da [29], eta arreta handia bereganatu du hainbat esparrutan (elikagai industrietan, kosmetikoetan, farmazeutikoetan...) bere biodegradagarritasunari, biobateragarritasunari eta toxikotasun gabeziari esker [30]. Gainera, lehen aipatutako contact-killing propietateari esker oso aztertua izan da bakterioen aurkako materialak sortzeko. Beste batzuen artean, Jinhong et al-ek. [19] kitosano/heparina multigeruzak sortu zituzten polietilen tereftalato substratuetan, eta modu eraginkorrean bakterioak kontaktuan hiltzen zituen materiala lortu zuten. Hongbin et al.-ek [22] berriz, kitosano/alginato multigeruzak sortu zituzten titanio substratuetan, eta bakterioen aurkako propietate oso onak zituen materiala lortu zuen.

Hala ere, kitosanoa ezin, esan daiteke biomaterial egokia denik, in vitro entseguetan fibroblastoen murrizketa lortzen duelako [31]. Horregatik, kitosanoa beste konposatu batzuekin erabili ohi da, eta azido hialuro-
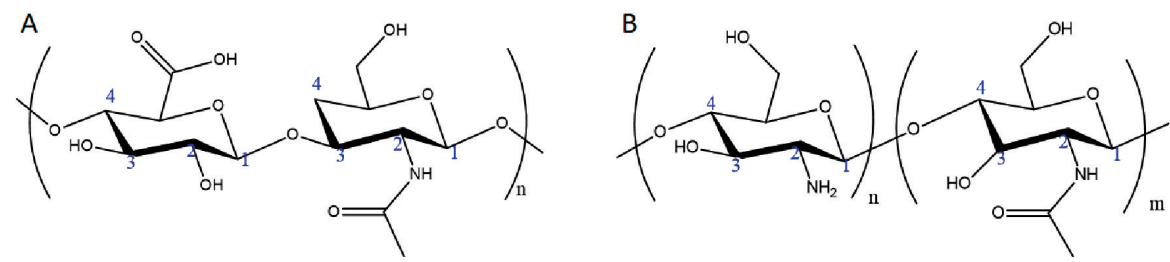

2. irudia. A) Azido hialuronikoa (HA) eta B) Kitosanoaren (CHI) errepresentazio eskematikoak. 
nikoarekin. konbinatuta erabiltzen denean LbL tekinikari esker, behatu da nola bakterioen adhesioa ekiditeaz gainera, fibroblastoen ugaritzea lortzen den [31].

Frogatu da oso propietate interesgarriak lortzen dituztela HA/CHI multigeruzek, hainbat gainazaletan eratzen direnean. Richert et al.-ek [32] HA/ CHI PEM-ak (10 bigeruza sortuz), behatu zuten Esterichia coli bakterioaren adhesioa \% 80-ean murrizten zutela, eta Jeroen et al.-ek ikusi zuten [33] HA/CHI multigeruzak sortu zituztenean PDMS gainazaletan, HAren hidrofilitate altuari esker proteinen adsortzioa ekiditzen zela. Adam $e t$ al.-ek [34] berriz, HA/CHI PEM-ak eratu zituzten polipropilenoan, eta erakutsi zuten multigeruzak ondo eratu zitezkeela gainazal hidrofobikoetan. Horrela, gurutzamendu altuko geruzak lortzen dira.

Lan honetan $\mathrm{HA} / \mathrm{CHI}$ multigeruzak eratu dira bi substratu desberdinen gainean LbL teknikaren moldagarritasuna frogatzeko. Alde batetik titanioa erabili da substratu ez- ezorganiko moduan, eta bestetik polietilen tereftalatoa substratu polimeriko moduan. Substratuen gainazalaren eraldaketa honen bidez haien biobateragarritasuna handitzea espero da, errefusak eta infekzioak ekiditen dituzten biomaterialak lortzeko modu erraz eta merke bat posiblea dela egiaztatuz.

\section{PROZEDURA}

\subsection{Materialak}

PET filmak (75 $\mu \mathrm{m})$ HIFI film industria izenekotik lortu dira. Panreac da filmen garbiketarako erabili den etanolaren hornitzailea, eta Panreac hornitzailearenak izan dira aminolisirako erabili diren metanola eta etilendiamina ere. Hurrenez hurren, \% 99,5 eta \% 99-ko purutasunekoak izan dira. Azido klorhidrikoa ere Panreac etxekoa izan da, \% 37koa.

Titanio-laginak Ti-6Al-4V aleaziokoak izan dira, CIDETEK hornitzailearenak. Laginen hidroxilaziorako, azido sulfurikoa $\left(\mathrm{H}_{2} \mathrm{SO}_{4}\right)$ (Panreac, \% 96) eta hidrogeno peroxidoa $\left(\mathrm{H}_{2} \mathrm{O}_{2}\right)$ (Foret, \% 30) erabili ziren. Silanizaziorako erabili zen 3-aminopropiltrietoxisilanoa Acros Organics etxekoa izan zen. \% 99eko purutasunekoa izan zen.

Multigeruzen eraiketarako kitosanoa (Sigma Aldrich, Medium Weight) eta azido hialuronikoa (Sigma Aldrich, 0,1-0,6 MDa) erabili ziren. Kitosanoa fluoreszenteki markatzeko isotiozianato fluoreszeina (FTIC) (Sigma Aldrich, >\% 90) erabili zen.

\subsection{Substratuen prestaketa}

Hasteko $4 \times 2 \mathrm{~cm}$-ko PET laginak garbitu dira etanolean eta uretan, 20 minutuz sonikatuz (3 aldiz). Behin gainazala guztiz lehortuta, aminoli- 
sia gauzatu da. Horretarako etilendiamina / metanol (40/60) ( $v / v)$ disoluzio batean murgildu dira 90 minutuz. Horrela, lagin bakoitza isolatu da, $50^{\circ} \mathrm{C}$ eta 200 rpm-an irabiatuz.

Ondoren, laginak $\mathrm{HCl}$ 0,1 M disoluzio batean 3 orduz eta inguru-tenperaturan irabiatuz aktibatu dira, eta huts-ponpa erabilita lehortu dira.

Titanio laginak 15 minutuz garbitu dira azetonan sonikatuz, ondoren etanoletan eta ondoren uretan. Azkenik, $\mathrm{N}_{2}$ gasa erabiliz lehortu dira.

Titaniozko laginak $\mathrm{H}_{2} \mathrm{SO}_{4}\left(\%\right.$ 96): $\mathrm{H}_{2} \mathrm{O}_{2}(\%$ 30) (3:1) nahaste batean sartuz hidroxilatu dira eta ordu batez irabiatzen mantendu dira. Ondoren, laginak \% $2(v / v)$ den 3-aminopropiltrietoxisilano disoluzioan sartu eta irabiatu dira beste ordu batez. Tratamendu honen ostean, laginak uraz ( 3 aldiz) eta azetonaz (5 aldiz) garbitu ziren, eta ondoren $\mathrm{N}_{2}$ gasa erabiliz lehortu ziren.

\subsection{FTIC-CHI disoluzioaren prestaketa}

FTIC-rekin markatutako kitosanoa lortzeko, $\mathrm{pH}=6,8$-ko CHI disoluzio bat prestatu zen $(1 \mathrm{~g} / \mathrm{L}-\mathrm{koa}, \% 1$ azido azetikotan), $\mathrm{NaOH}$ disoluzio kontzentratu batekin doituz. Disoluzio hori $(100 \mathrm{~mL}) 2 \mathrm{~g} / \mathrm{L}$ (metanoletan) den FTIC disoluzio batekin $(50 \mathrm{~mL})$ nahastu ondoren, 20 orduz ilunpean mantendu zen irabiaketa konstantepean. Amaitzeko, disoluzioa dializatu egin zen hainbat aldiz, metanol:ura $(70: 30, v / v)$ nahastean fluoreszentzia desagertu arte.

\subsection{Multigeruzen eraiketa}

10 eta 11 geruza eratu dira. Alegia, 5 eta 5,5 HA/CHI bigeruza eratu dira. Hasteko, PET eta Titanio aminofuntzionalizatuen laginak erabili dira, eta $1 \mathrm{~g} / \mathrm{L}$ den azido hialuroniko disoluzio batean murgildu dira 15 minutuz. Segidan, $\mathrm{pH}=5$ duen disoluzio indargetzailean garbitu dira.

Ondoren, $1 \mathrm{~g} / \mathrm{L}$-ko kontzentrazioa duen CHI disoluzio batean 15 minutuz murgildu dira eta $\mathrm{pH}=5$-ko disoluzio indargetzailean ere garbitu dira. Bi disoluzio hauetan (HA eta $\mathrm{CHI}$ ) murgiltzeko prozedura errepikatu da geruza kopuru jakin bat a lortu arte. Hori bukatuta, laginak ur destilatuan garbitu dira gatz-arrastoak kentzeko. 3. irudian laburtzen da multigeruzak sortzeko prozeduraren eskema.

Fluoreszentziadun multigeruzak sortzeko emandako urratsak aurrekoen berdinak izan dira, baina kitosanoa erabili ordez, FTIC-rekin markaturiko kitosanodun disoluzioa erabili da, $1 \mathrm{~g} / \mathrm{L}-\mathrm{koa}$. 


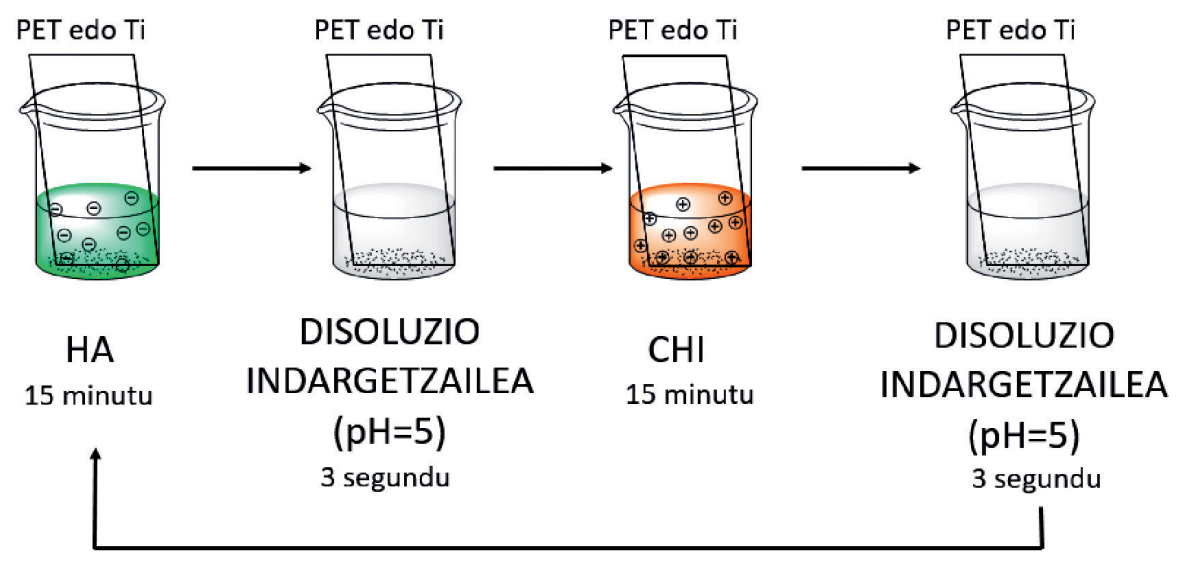

3. irudia. Multigeruzak sortzeko jarraitutako urratsak.

\subsection{Karakterizazio-teknikak}

X-Izpiko espektrokopia fotoelektronikoa (XPS)

Substratuen gainazaleko konposizioa aztertu zen Phoibos 150 1D-DLD tresnaz baliatuz, eta iturri gisa Focus 500 erradiazio monokromatikoa erabilita, Al/Ag anodo dualarekin.

\section{Konfokal mikroskopia fluoreszentea}

FTIC-rekin markaturiko kitosanodun multigeruzen gainazala aztertu zen, Olympus FluoView-FV500 mikroskpio konfokalaz baliatuz.

\section{Kontaktu-angelua}

Gainazalen kontaktu-angeluaren neurketak Neurtek Dataphysics OCA 15EC Instruments sistema optikoa erabilita egin ziren, $2 \mu \mathrm{L}$-ko ur destilatu tantak erabiliz neurketa bakoitzean.

\section{EMAITZAK}

\subsection{Substratuen aktibazioa}

Bi substratuek arazo bera aurkezten dute: substratu geldoak dira. Beraz, polisakaridoen atxikimendua ahalbidetzeko, lehendabizi gainazalaren aktibazioa gauzatu behar da. Hori bi eratara egin daiteke. Lehenik, plasma erabil daiteke (materiaren laugarren egoeran, gasaren antzera aina ionizatutako partikulak dituelarik). Bigarrenik, kimikoki ere egin daiteke. Azken 
era horretara egiten bada, hainbat erreakzio posible ditugu funtzio talde ezberdinak sartzeko. Pérez-Álvarez et al.-ek [26] polietilen tereftalatoaren hidrolisia gauzatu zuten gainazala aktibatzeko. Chua et al.-ek [35] berriz, titanioaren gainazala aktibatu beharrean funtzio talde bat sartuz, PEI geruza aitzindari bat kokatu zuten ondorengo geruzen atxikimendua bermatzeko, eta Thierry et al.-ek [36] gauza bera egin zuten Ni-Ti materialetan.

Lan honetan bi substratuen gainazala funtzionalizatu da amino taldeekin, karga positiboak ezartzeko eta horrela polianioia egonkorrago atxikitua geratu ahal izateko.

Polietilen tereftalatoaren kasuan, aminolisi bat egin da etilendiamina erabiliz. Horrela, diaminek eraso nukleofilikoa egiten dute ester-loturetan.
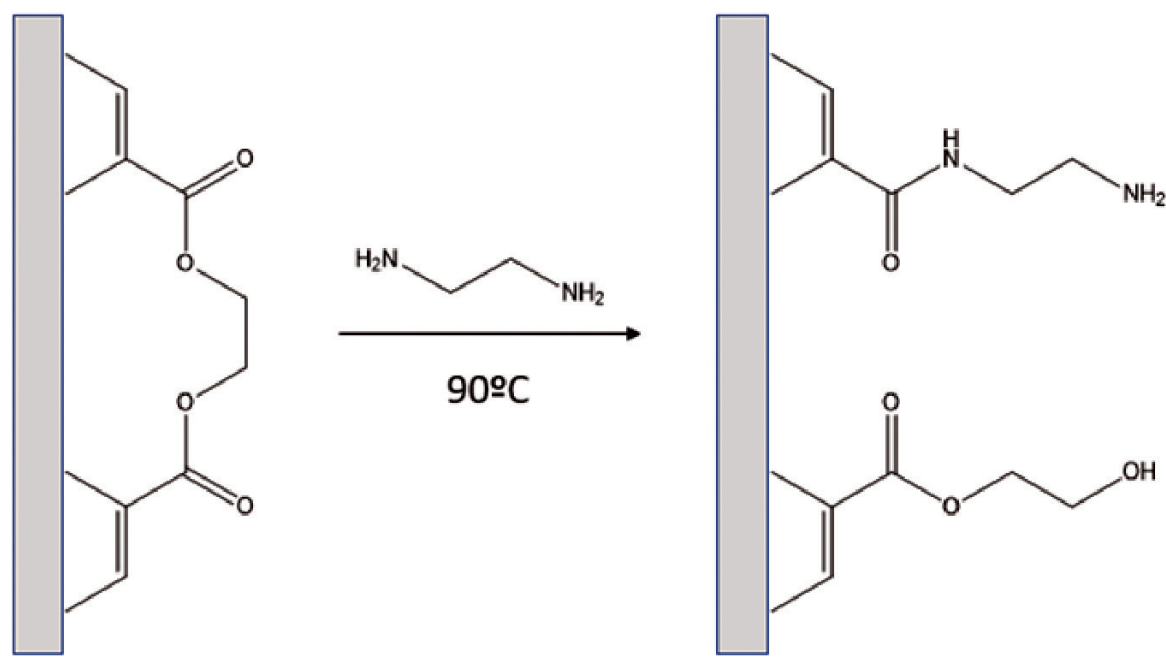

4. irudia. PET-aren etilendiaminaren bidezko aminolisiaren irudi eskematikoa.

Titanioaren kasuan berriz, amino-funtzionalizatutako gainazal aminofuntzionatua lortzeko, lehenengo hidroxilazioa gauzatzen da eta ondoren silanizazio baten bidez lor daitezke amino taldeak, Lv et al.-ek [22] proposatu zuten metodoari jarraituz (5. irudia).
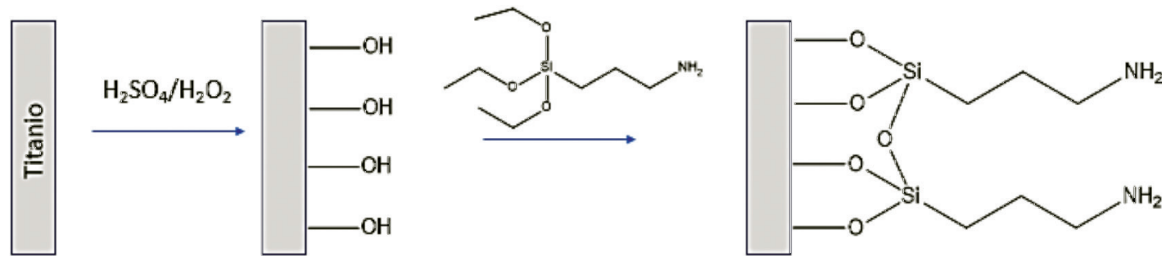

5. irudia. Titanioaren amina taldeak ezartzeko irudi eskematikoa. 
Gainazala amino-funtzionalizatu egin dela bermatzeko XPS bidez aztertu da prozesua, gainazalaren konposizioa jakiteko.

1. eta 2. taulan ikusten den moduan, nitrogenoa ikusi zen bai titanioan, bai polietilen tereftalatoan $-\mathrm{NH}_{2}$ taldeak txertatzearen ondorioz, funtzionalizazio errakzioak modu arrakastatsu batean gertatu zirela frogatuz.

1. taula. XPS-n lortutako konposizioa aminolizatutako polietilen tereftalatoaren gainazalean.

\begin{tabular}{ccc}
\hline & PET & Aminolizatutako PET \\
\hline$\% \mathrm{C}$ & 73,5 & 71,0 \\
$\% \mathrm{O}$ & 26,5 & 27,5 \\
$\% \mathrm{~N}$ & 0,0 & 1,5 \\
\hline
\end{tabular}

2. taula. XPS-n lortutako konposizioa $-\mathrm{NH}_{2}$ funtzionalizatutako titanioaren gainazalean.

\begin{tabular}{crc}
\hline & \multicolumn{1}{c}{$\mathrm{Ti}$} & Aminolizatutako Ti \\
\hline$\% \mathrm{C}$ & 46 & 34,3 \\
$\% \mathrm{O}$ & 40,7 & 48,1 \\
$\% \mathrm{Ti}$ & 12,7 & 14,9 \\
$\% \mathrm{~N}$ & 0,6 & 2,7 \\
\hline
\end{tabular}

\subsection{Multigeruzen eraketaren bermatzea}

\subsubsection{Fluoreszentzia}

Oso aztertua izan da multigeruzen hazkuntzaren bermatzea FTIC-rekin markaturiko kitosanoa erabiliz. Izan ere, LbL prozesuari jarraitzeko oso erabilgarria dela ikusi da. Izatez, beste batzuen artean, Liu et al-ek. [16] LbL metaketa aztertu zuten korindroin sulfato eta FTIC-CHI multigeruzadun PET filmetan, eta UV-Vis espektroskopiari esker geruzen hazkundea egiaztatu zuten.

$\mathrm{Fu}$ et al.-ek [19] ere, beste askoren moduan metodo hau erabili zuten heparina eta FTIC-CHI multigeruzak sortzeko PET-ean.

Horregatik, HA/FTIC-CHI multigeruzak sortu ziren, bai PET-ean, bai titanioan;konfokal mikroskopioko irudien bidez ikusi zen fluoreszentziaren 
hazkundea. 6. irudian polietilen tereftalatoan HA/FTIC-CHI multigeruzen ondorioz areagotzen den fluoreszentzia beha daiteke, eta 7. irudian gauza bera titanioaren kasuan.

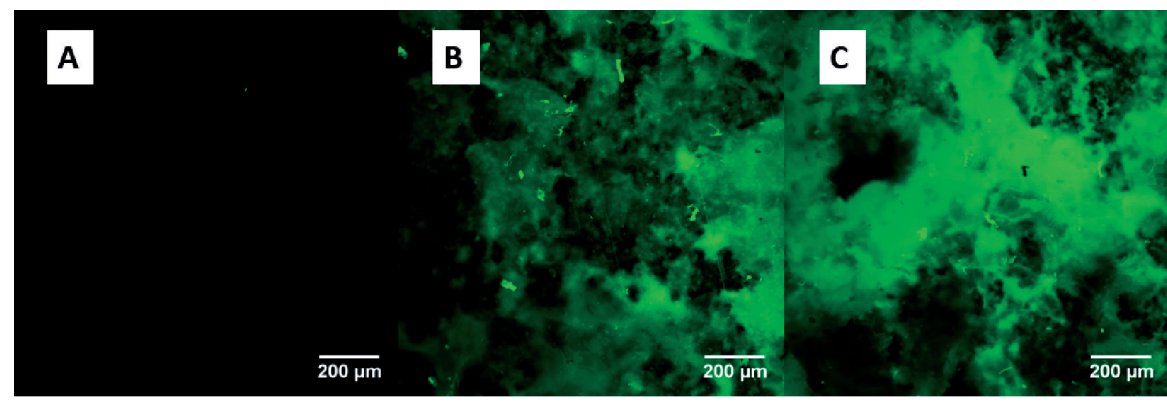

6. irudia. polietilen tereftalatoan sortutako HA/CHI-FTIC multigeruzen irudiak mikroskopio konfokalean: A) Geruzarik gabe, B) 10 geruzekin eta C) 20 geruzekin.

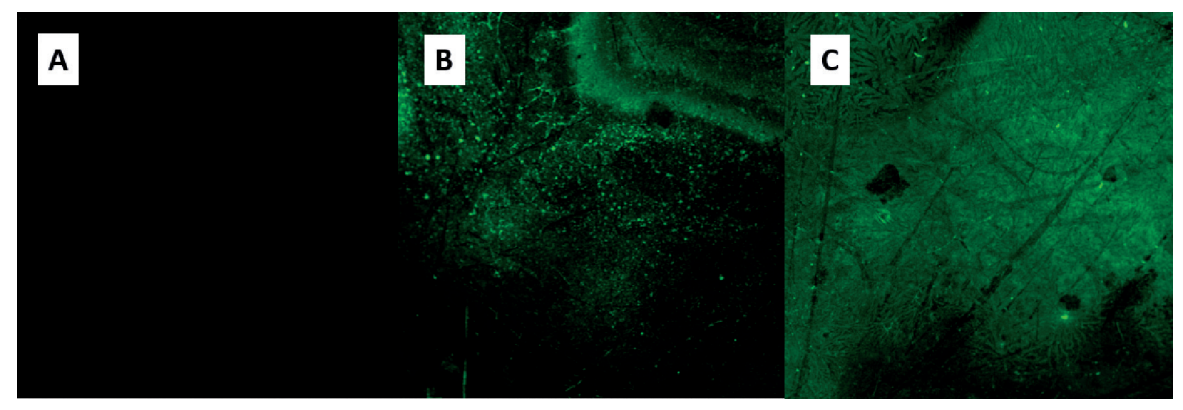

7. irudia. titanioan sortutako HA/CHI-FTIC multigeruzen irudiak konfokal mikroskopioan: A) Geruzarik gabe, B) 10 geruzekin eta C) 20 geruzekin.

\subsubsection{Kontaktu angelua}

Dakigunez, HA naturako molekula hidrofilikoenetariko bat da [38], eta kitosanoa berriz ez da hain hidrofilikoa; izan ere kitosanoaren disolbagarritasuna oso mugatua da eta soilik inguru azidotan da disolbagarria. Beraz geruzak atxikitzen direla froga daiteke metodo sinple honen bidez, gainazalean azken geruza HA denean eta CHI denean lortzen den kontaktu angelua konparatuz. 8. irudian ikus daitezke polietilen tereftalatoan lortutako kontaktu-angeluak, eta 9. irudian titanioan lortutakoak. 


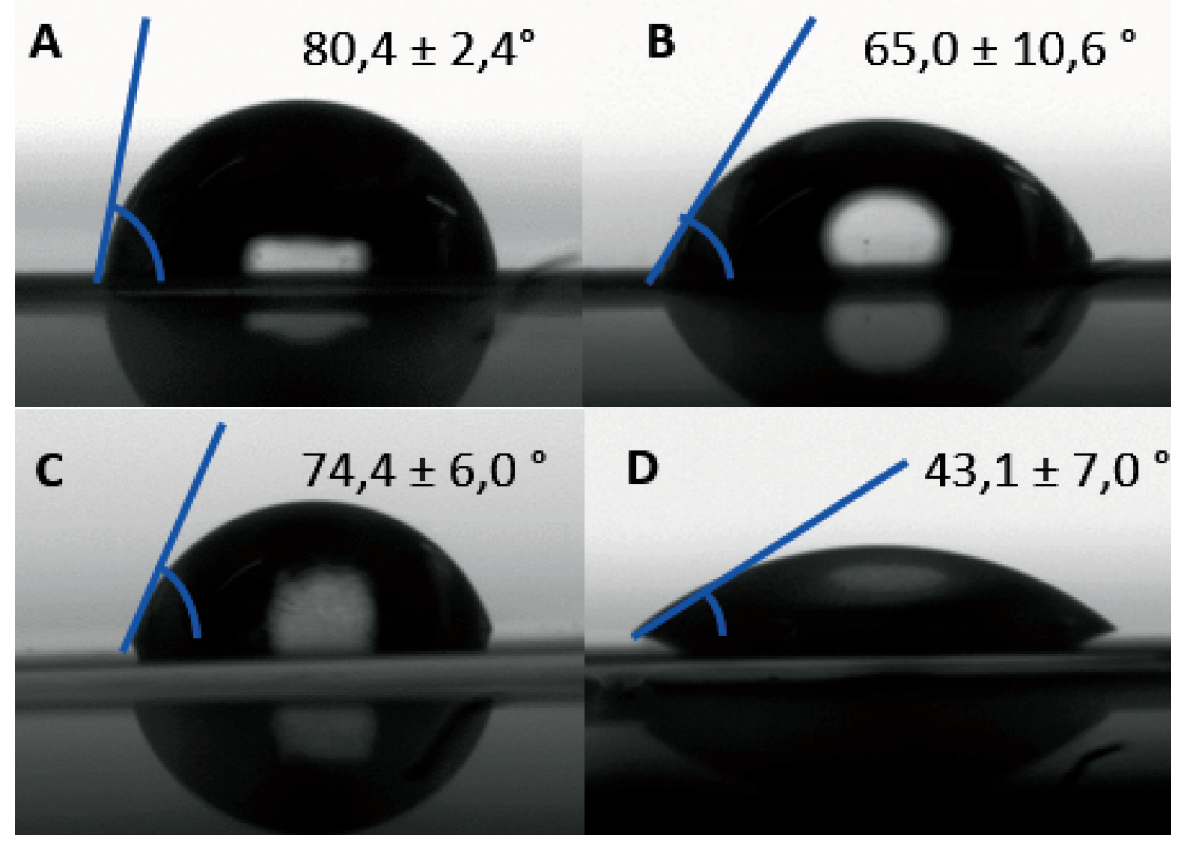

8. irudia. PET-aren gaineko kontaktu-angeluak A) garbia, B) aminolizatua, C) 10 geruzekin eta D) 11 geruzekin.

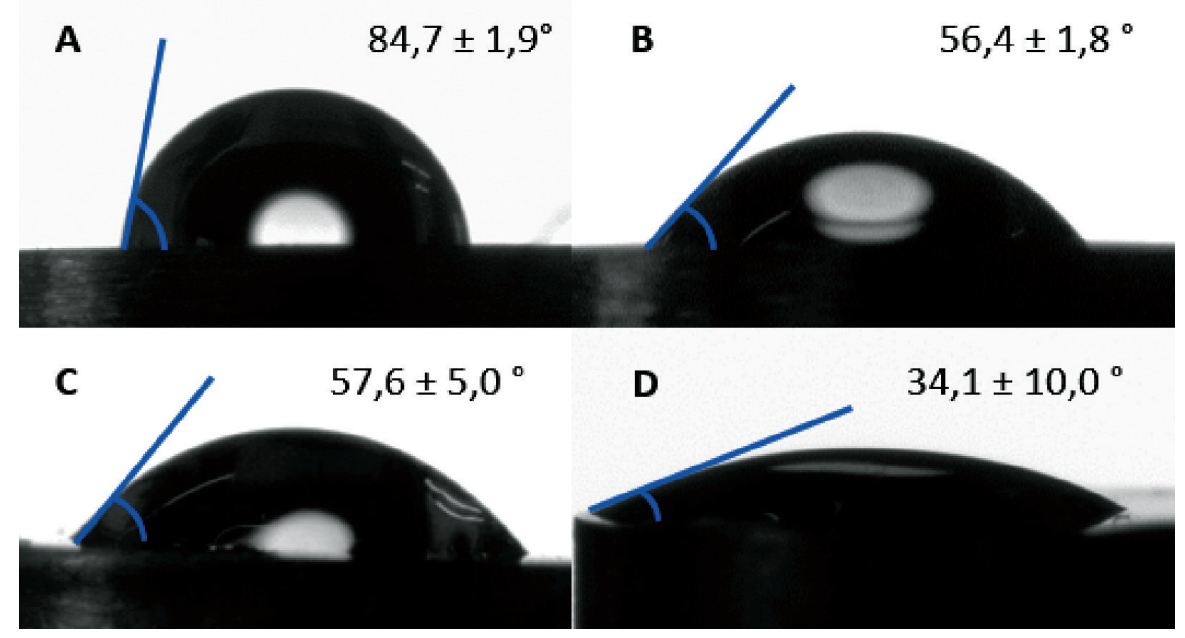

9. irudia. Titanioaren gaineko kontaktu-angeluak A) garbia, B) aminolizatua, C) 10 geruzekin eta D) 11 geruzekin. 
Ikusten den moduan, bi hasierako substratuak hidrofobikoak dira, tratamendurik jaso ez dutenean beraien kontaktu-angeluak $\sim 80^{\circ}$-koak baitira; hala ere, kontaktu-angelua murriztu egiten da gainazala amino-funtzionalizatu ondoren, hau da, talde hidrofiliko hauek ezarri ondoren. Avadanei et al.-ek [37] PET gainazalen aminolisia aztertu zuten, eta behatu zuten nola kontaktu-angeluaren murriztea gertatzen zen, hau da, hidrofilitatea igo egiten zen amino taldeen kontzentrazio handipenari esker.

Honetaz gain, frogatu da CHI eta HA gainazaleko azken geruza bezala ezartzeak kontaktu-angeluan eragina duela. Egia esan, aldaketa nabaria ikusi da, kontaktu- angeluan 10 geruza edo 11 geruza izanik. Izan ere, 10 geruzako substratuetan, azken geruza kitosanozkoa da, lehen esan den bezala hidrofobikoagoa; 11 geruza ditugunean berriz, azido hialuroniko hidrofilikoa dago gainazalean, eta materialaren hidrofilitatea nabarmenki handiagoa da.

\section{ONDORIOAK}

HA/CHI multigeruzak titanioan eta polietilen tereftalatoan sortu dira. Horretarako, laginak geldoak direnez amino-funtzionalizatu egin dira eta ondorioz , XPS teknikaren bidez erreakzioa gertatu dela egiaztatu da. Multigeruzak ondo eratu direla ziurtatzeko, FTIC-rekin markaturiko kitosanoa erabili da, eta ikusi da fluoreszentzia geruza kantitatearekin handitzen zela, konfokal mikroskopioan.

Kontaktu-angeluaren neurketari esker, behatu da materialaren hidrofilitatea asko handitzen dela multigeruzak sortu ondoren, eta bereziki hialuronikoa azken geruza denean, kontaktu-angelu oso baxuak lortzen dira. Materialak bereganatzen duen hidrofilitate hau biobateragarritasuna lortzeko garrantzitsua izan daiteke, protesi hidrofilikoek errefus gutxiago aurkezten dutelako.

Hau guztia ikusita, ondoriozta dezakegu LbL metodoa eraginkorra dela, bai material ezorganikoen, bai material polimerikoen gainazalen eraldaketa egiteko materialen biobateragarritasuna handitzean; ondorioz, hidrofilitate altuko materiala lortzen da eta material horrek bakterioen biofilmak ekidin ditzake; horrela, irtenbide erraz eta merkea aurkitu zaio gaur egun inplante artifizialek daukaten arazo nagusiari.

\section{ESKER ONAK}

Egileek SGIkerrek (UPV/EHU, MICINN; GV/EJ, ERDF eta EGIF) emandako laguntza (FRONTIERS, ELKARTEK programa, Ikerkuntza taldeak IT718-13) teknikoa eta gizatiarra eskertzen dute. 


\section{BIBLIOGRAFIA}

[1] R. GONZALEZ. 2009. «Origen y evolución de los implantes dentales». Rev. Habanera Ciencias Medicas, $8,9$.

[2] K.G. NEOH, X. HU, D. ZHENG, eta E.T. KANG. 2012. «Balancing osteoblast functions and bacterial adhesion on functionalized titanium surfaces». Biomaterials, vol. 33, 10, 2813-2822.

[3] O.E.M. POHLER. 2000. «Unalloyed titanium for implants in bone surgery». Injury, 31, S-D7-13.

[4] N. GOUR, K.X. NGO, eta C. VEBERT-NARDIN. 2014. «Anti-infectious surfaces achieved by polymer modification». Macromol. Mater. Eng., 299, 648-668.

[5] T.G. MACKAY, D.J. WHEATLEY, G.M. BERNACCA, A.C. FISHER, eta C.S. HINDLE. 1996. «New Polyurethane Heart Valve Prosthesis: design, manufacturing and evaluation». Biomaterials, 17, 1857-1863.

[6] G.M. BERNACCA, T.G. MACKAY, R. WILKINSON, eta D.J. WHEATLEY. 1997. «Polyurethane heart valves: Fatigue failure, calcification, and polyurethane structure». J. Biomed. Mater. Res., 34, 371-379.

[7] S. LAVAUD et al. 2003. «Optimal anticoagulation strategy in haemodialysis with heparin-coated polyacrylonitrile membrane». Nephrol. Dial. Transplant., 18, 2097-2104.

[8] B.A. HOLDEN. 1989. «The Ocular Response to Contact Lens Wear». Optom. Vis. Sci., vol. 66, 11, 717-733.

[9] M.G. CARNEIRO-DA-CUNHA et al. 2010. «Physical and thermal properties of a chitosan/alginate nanolayered PET film». Carbohydr. Polym., 82, 153-159.

[10] B. CARPENTIER eta O. CERF. 1993. «Biofilms and their consequences, with particular reference to hygiene in the food industry». J. Appl. Bacteriol., 75, 499-511.

[11] J. RODRÍGUEZ-HERNÁNDEZ. 2017. Polymers against Microorganisms.

[12] T.F.C. MAH eta G.A. O'TOOLE. 2001. «Mechanisms of biofilm resistance to antimicrobial agents». Trends Microbiol., 9, 34-39.

[13] G.A. JUNTER, P. THÉBAULT, eta L. LEBRUN. 2016. «Polysaccharidebased antibiofilm surfaces». Acta Biomater., 30, 13-25.

[14] J.C. TILLER, S.B. LEE, K. LEWIS, eta A.M. KLIBANOV. 2002. «Polymer surfaces derivatized with poly(vinyl-N-hexylpyridinium) kill airborne and waterborne bacteria». Biotechnol. Bioeng., 79, 465-471.

[15] E.I. RABEA, M.E.-T. BADAWY, C.V. STEVENS, G. SMAGGHE, eta W. STEURBAUT. 2003. «Chitosan as Antimicrobial Agent: Applications and Mode of Action». Biomacromolecules, 4, 1457-1465.

[16] Y. LIU, T. HE, eta C. GAO. 2005. «Surface modification of poly(ethylene terephthalate) via hydrolysis and layer-by-layer assembly of chitosan and chondroitin sulfate to construct cytocompatible layer for human endothelial cells». Colloids Surfaces B Biointerfaces, vol. 46, 2, 117-126. 
[17] Q. TAN, J. JI, M.A. BARBOSA, C. FONSECA, eta J. SHEN. 2003. «Constructing thromboresistant surface on biomedical stainless steel via layer-bylayer deposition anticoagulant». Biomaterials, 24, 4699-4705.

[18] Y. YANG, Q. HE, L. DUAN, Y. CUI, eta J. LI. 2007. «Assembled alginate/ chitosan nanotubes for biological application». Biomaterials, 28, 3083-3090.

[19] J. FU, J. JI, W. YUAN, eta J. SHEN. 2005. «Construction of anti-adhesive and antibacterial multilayer films via layer-by-layer assembly of heparin and chitosan». Biomaterials, 26, 6684-6692.

[20] W.B. STOCKTON eta M.F. RUBNER. 1997. «Molecular-Level Processing of Conjugated Polymers. 4. Layer-by-Layer Manipulation of Polyaniline via Hydrogen-Bonding interactions». Macromolecules, 30, 2717-2725.

[21] B.L. WANG, K.F. REN, H. CHANG, J.L. WANG, eta J. JI. 2013. «Construction of degradable multilayer films for enhanced antibacterial properties». ACS Appl. Mater. Interfaces, 5, 4136-4143.

[22] H. LV, Z. CHEN, X. YANG, L. CEN, X. ZHANG, eta P. GAO. 2014. «Layer-by-layer self-assembly of minocycline-loaded chitosan/alginate multilayer on titanium substrates to inhibit biofilm formation». J. Dent., vol. 42, 11, 1464-1472.

[23] J.A. LICHTER, K.J. VAN VLIETPA, eta M.F. RUBNER. 2009. «Design of antibacterial surfaces and interfaces: Polyelectrolyte multilayers as a multifunctional platform». Macromolecules, vol. 42, 22, 8573-8586.

[24] J.D. MENDELSOHN, S.Y. YANG, J.A. HILLER, A.I. HOCHBAUM, eta M.F. RUBNER. 2003. «Rational design of cytophilic and cytophobic polyelectrolyte multilayer thin films». Biomacromolecules, vol. 4, 1, 96-106.

[25] S. DEL HOYO-GALLEGO et al. 2016. «Construction of antibacterial poly(ethylene terephthalate) films via layer by layer assembly of chitosan and hyaluronic acid». Carbohydr. Polym., 143, 35-43,

[26] L. PÉREZ-ÁlVAREZ, E. LIZUNDIA, S. DEL HOYO, A. SAGASTI, L.R. RUBIO, eta J.L. VILAS. 2016. «Polysaccharide polyelectrolyte multilayer coating on poly(ethylene terephthalate)». Polym. Int., 65, 915-920,

[27] A. MERO eta M. CAMPISI. 2014. «Hyaluronic acid bioconjugates for the delivery of bioactive molecules». Polymers (Basel)., 6, 346-369.

[28] S.K. HAHN eta A.S. HOFFMAN, 2004. «Characterization of Biocompatible Polyelectrolyte Complex Multilayer of Hyaluronic Acid and Poly-L-Lysine». Biotechnol. Bioprocess Eng., 9, 179-183.

[29] P. KUJAWA, P. MORAILLE, J. SANCHEZ, A. BADIA, eta F.M. WINNIK. 2005. «Effect of molecular weight on the exponential growth and morphology of hyaluronan/chitosan multilayers: A surface plasmon resonance spectroscopy and atomic force microscopy investigation». J. Am. Chem. Soc., 127, 9224-9234.

[30] W. XIA, P. LIU, J. ZHANG, eta J. CHEN. 2011. «Biological activities of chitosan and chitooligosaccharides». Food Hydrocoll., 25, 170-179. 
[31] C.-H. JOU et al. 2007. «Biocompatibility and Antibacterial Activity of Chitosan and hyaluronic Acid Inmobilized Polyester Fibers». J. Appl. Polym. Sci., 104, 220-225.

[32] L. RICHERT et al. 2004. «Layer by Layer Buildup of Polysaccharide Films: Physical Chemistry and Cellular Adhesion Aspects». Langmuir, 20, 448458.

[33] J.H.H. BONGAERTS, J.J. COOPER-WHITE, eta J.R. Stokes. 2009. «Low biofouling chitosan-hyaluronic acid multilayers with ultra-low friction coefficients». Biomacromolecules, vol. 10, 5, 1287-1294.

[34] A.L. LARKIN, R.M. DAVIS, eta P. RAJAGOPALAN. 2010. «Biocompatible, detachable, and free-standing polyelectrolyte multilayer films». Biomacromolecules, 11, 2788-2796.

[35] P.H. CHUA, K.G. NEOH, E.T. KANG, eta W. WANG. 2008. «Surface functionalization of titanium with hyaluronic acid/chitosan polyelectrolyte multilayers and RGD for promoting osteoblast functions and inhibiting bacterial adhesion». Biomaterials, 29, 1412-1421.

[36] B. THIERRY, F.M. WINNIK, Y. MERHI, J. SILVER, eta M. TABRIZIAN. 2003. «Bioactive coatings of endovascular stents based on polyelectrolyte multilayers». Biomacromolecules, 4, 1564-1571.

[37] M. AVADANEI, M. DROBOTA, I. STOICA, E. RUSU, eta V. BARBOIU. 2010. «Surface morphology and amide concentration depth profile of aminolyzed poly(ethylene terephthalate) films». J. Polym. Sci. Part A Polym. Chem., 48, 5456-5467.

[38] J. NECAS, L. BARTOSIKOVA, P. BRAUNER, eta J. KOLAR. 2008. «Hyaluronic acid (hyaluronan): A review». Vet. Med.(Praha)., 53, 397-411. 